\title{
Attitudes toward people with mental illness among medical students
}

\author{
Vijayalakshmi Poreddi, Rohini Thimmaiah ${ }^{1}$, Suresh Bada Math ${ }^{2}$ \\ Departments of Nursing, College of Nursing, and ${ }^{2}$ Psychiatry, National Institute of Mental Health and Neuro Sciences, ${ }^{1}$ Department of \\ Psychiatry, Vydehi Institute of Medical Sciences and Research Center, Bengaluru, Karnataka, India
}

\begin{abstract}
Background: Globally, people with mental illness frequently encounter stigma, prejudice, and discrimination by public and health care professionals. Research related to medical students' attitudes toward people with mental illness is limited from India. Aim: The aim was to assess and compare the attitudes toward people with mental illness among medical students'. Materials and Methods: A cross-sectional descriptive study design was carried out among medical students, who were exposed $(n=115)$ and not exposed $(n=61)$ to psychiatry training using self-reporting questionnaire. Results: Our findings showed improvement in students' attitudes after exposure to psychiatry in benevolent $(t=2.510, P<0.013)$ and stigmatization $(t=2.656, P<0.009)$ domains. Further, gender, residence, and contact with mental illness were the factors that found to be influencing students' attitudes toward mental illness. Conclusion: The findings of the present study suggest that psychiatric education proved to be effective in changing the attitudes of medical students toward mental illness to a certain extent. However, there is an urgent need to review the current curriculum to prepare undergraduate medical students to provide holistic care to the people with mental health problems.
\end{abstract}

Key words: Attitudes, curriculum, medical students, psychiatry

\section{Introduction}

Globally, people with mental illness frequently encounter stigma, prejudice, and discrimination not only by the public, but also by the health care providers ${ }^{[1,2]}$ According to World Health Organization, it was estimated that there are 450 million people in the world currently suffering from some kind of mental illness and constitutes $14 \%$ of the global burden of disease. ${ }^{[3]}$ The prevalence of mental disorders in India is high, as in other parts of the world. ${ }^{[4]}$ It was estimated that at least 58/1000 people have a mental illness and about 10 million Indians suffer from severe mental illness. ${ }^{[5,6]}$ On the other hand, there is paucity of psychiatrists in India, that is, $<0.5 / 100,000$ population. ${ }^{[7]}$

\begin{tabular}{|l|l|}
\hline \multicolumn{2}{|c|}{ Access this article online } \\
\hline Quick Response Code: & Website: \\
\hline & www.ruralneuropractice.com \\
\cline { 2 - 3 } & \\
\hline & \\
\hline
\end{tabular}

Published evidence clearly indicates unfavorable attitudes among medical students toward people with mental illness. ${ }^{[8,9]}$ Further, in a recent study from India, it was found that undergraduate medical students have multiple lacunae in knowledge toward psychiatry, psychiatric disorders, psychiatric patients and psychiatric treatment. ${ }^{[8]}$ In addition, previous research established evidence that psychiatry was not top choice of specialty for medical students. ${ }^{[10-12]}$ However, undoubtedly psychiatric experience plays a significant role in changing the attitudes of students toward psychiatry. On the other hand, earlier studies from India indicate that minimum $20-50 \%$ of patients attending Primary Health Centers have major mental disorders. ${ }^{[13]}$ Contemporarily, health care professionals can no longer ignore mental health, as it will play an increasingly important role in the care of all patients. Further, the negative attitudes of doctors may compromise the quality of life and self-esteem of patients. ${ }^{[14]}$ Thus, assessing the attitudes of medical students toward mental illness is of greatest concern since they come across patients with different mental health problems. Very few studies from India assessed the impact of psychiatric exposure in changing

Address for correspondence:

Dr. Rohini Thimmaiah, Department of Psychiatry, Vydehi Institute of Medical Sciences and Research Center, Bengaluru, Karnataka, India. E-mail: drrohinimd@gmail.com 
the attitudes of medical students toward people with mental illness. ${ }^{[15-17]}$ It is therefore, the present study was aimed to examine the attitudinal differences between students those have undergone psychiatric training exposure and those who have not, toward people with mental illness.

\section{Materials and Methods}

This was a cross-sectional descriptive study carried out at a private medical college, South India.

Participants were selected through convenient sampling. Study criteria included; (a) medical students $\left(1^{\text {st }}\right.$ and $2^{\text {nd }}$ year medical students) those did not have psychiatry exposure, (b) final year students those undergone theory and clinical rotation including 2 weeks of internship, (c) students those were willing to participate. A sample of 193 students $\left(1^{\text {st }}\right.$ and $2^{\text {nd }}$ year $n=126$, the final year $n=67$ ) was eligible to participate in the study. However, we could not meet six of the final year students and five of the students from $1^{\text {st }}$ to $2^{\text {nd }}$ year were absent during data collection. Six of the questionnaires were incomplete. Therefore, the final sample consisted of 176 students $\left(n=115,1^{\text {st }}\right.$ and $2^{\text {nd }}$ year and 61 final year $)$ with $91.1 \%$ response rate.

\section{Measures}

\section{Demographic data survey instrument}

The demographic form consists of five items to seek the background of the participants in the study that include "age, education, residence, and contact with mental illness."

\section{Attitude scale for mental illness}

This was a valid and reliable (Cronbach's Alpha 0.86), self-report measure used to measure health professionals attitudes toward persons with mental illness. ${ }^{[18]}$ This modified version of the questionnaire measures opinions about mental illness in Chinese community. This was a 5-point Likert scale rated participants responses from totally disagree (1) to totally agree (5). The lower scores indicate positive attitudes toward persons with mental illness.

\section{Separatism}

Includes ten items, (1-9, and 24) to measure respondents' attitude of discrimination e.g.: "People with mental illness have unpredictable behaviour."

\section{Stereotyping}

Includes four items (10-13) intended to measure the degree of respondents' maintenance of social distance toward persons with mental illness. E.g.: "It is easy to identify those who have a mental illness."

\section{Restrictiveness}

Composed of four items (14-17), that hold an uncertain view on the rights of people with mental illness. E.g.: "It is not appropriate for a person with mental illness to get married."

\section{Benevolence (reverse coded)}

Includes eight items (18-23, 25 and 26) related to kindness and sympathetic views of the respondents toward people with mental illness e.g.: "People with mental illness can hold a job."

\section{Pessimistic prediction}

Composed of four items (27-30) intended to measure the level of prejudice toward mental illness e.g.: "It is harder for those who have a mental illness to receive the same pay for the same job."

\section{Stigmatization}

Includes four items (31-34) that measure the discriminatory behavior of the students toward mental illness.

\section{Procedure}

Data was collected a batch-wise in their classrooms after completion of the regular lectures. On the introduction, the primary author explained briefly about aims and methods of the present study to all the participants. Students those were willing to participate were asked to complete the questionnaires. They could complete both questionnaires in about $20 \mathrm{~min}$. Data collection tools contained no identifying information (such as name, address, mobile number, etc.,) and therefore kept the individual responses confidential.

\section{Ethical considerations}

Permission was obtained from the administrators of the colleges where the study was conducted. Participants were introduced to the aims and procedures of the study to decide if they would like to participate. After they had agreed to participate verbally, the researchers gave them the confidential questionnaire. Participants were given freedom to withdraw from the study at any part of the procedure.

\section{Statistical analysis}

The response of the benevolence domain was reverse coded before the analysis. The data were analyzed using appropriate statistical software and results were presented in narratives and tables. The $t$-test was used to determine whether significant differences existed between medical and nursing students regarding mean attitudes scores. Chi-square test was used to find the significant association between 